\title{
Guidelines
}

Skin

Appendage

Disorders

\section{Treatment of Seborrhoeic Dermatitis in Asia: A Consensus Guide}

\author{
Wai Kwong Cheong ${ }^{a}$ Chi Keung Yeung ${ }^{b}$ Raghunandan Govind Torsekar ${ }^{c}$ \\ Dae Hun Suh $^{d}$ Rataporn Ungpakorn ${ }^{e}$ Sandra Widaty ${ }^{f}$ Noor Zalmy Azizan ${ }^{g}$

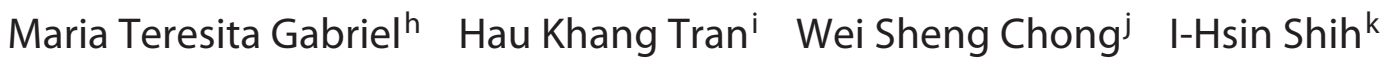 \\ Federica Dall'Oglio' Giuseppe Micali'
}

\begin{abstract}
a Specialist Skin Clinic, Singapore, Singapore; ${ }^{b}$ Division of Dermatology, Department of Medicine, University of Hong Kong, Hong Kong; ' ${ }^{D}$ epartment of Dermatology, Rajiv Gandhi Medical College and Chatrapathi Shivaji Maharaj Hospital, Kalwa, Thane, India; d Department of Dermatology, Seoul National University College of Medicine, Seoul, South Korea; ${ }^{\text {SSkin }}$ and Aesthetic Lasers Clinic, Bumrungrad International Hospital, Bangkok, Thailand; ${ }^{f}$ Department of Dermato-Venereology and Medical Education Department, Universitas Indonesia, Kota Depok, Indonesia; gDepartment of Dermatology, Hospital Kuala Lumpur, Kuala Lumpur, Malaysia; ${ }^{\text {h} D e p a r t m e n t ~ o f ~ D e r m a t o l o g y, ~}$ Research Institute for Tropical Medicine, Manila, Philippines; 'National Hospital of Dermatology and Venereology, Hanoi, Vietnam; 'Dermatology Unit, Department of General Medicine, Khoo Teck Puat Hospital, Singapore, Singapore; 'Department of Pediatric Dermatology, Chang Gung Children's Hospital, Taipei, Republic of China; 'Dermatology Clinic, University of Catania, Catania, Italy'
\end{abstract}

\section{Key Words}

Seborrhoeic dermatitis · Asia · Treatment · Diagnosis · Consensus

\footnotetext{
Abstract

Seborrhoeic dermatitis (SD) is common in Asia. Its prevalence is estimated to be $1-5 \%$ in adults. However, larger population-based studies into the epidemiology of SD in Asia are lacking, and the aetiology of SD may differ widely from Western countries and in different parts of Asia. In addition, clinically significant differences between Asian and Caucasian skin have been reported. There is a need to define standardized clinical diagnostic criteria and/or a grading system to help determine appropriate treatments for SD within Asia. With this in mind, experts from India, South Korea, Taiwan, Malaysia, Vietnam, Singapore, Thailand, the Philippines, Indonesia, and Italy convened to define the landscape of SD in
}

Asia at a meeting held in Singapore. The consensus group developed a comprehensive algorithm to aid clinicians to recommend appropriate treatment of SD in both adults and children. In most cases, satisfactory therapeutic results can be accomplished with topical antifungal agents or topical corticosteroids. Non-steroidal anti-inflammatory agents with antifungal properties have been shown to be a viable option for both acute and maintenance therapy.

(c) 2016 S. Karger AG, Basel

\section{Introduction}

Seborrhoeic dermatitis (SD) is a common chronic inflammatory disease of the skin, which manifests as scaly reddish-brown itchy patches in sebaceous, gland-rich regions of the scalp, face, and trunk [1]. It affects both children and adults, with a higher incidence in infancy and

\section{KARGER 125}

C 2016 S. Karger AG, Basel

2296-9195/16/0014-0187\$39.50/0
Giuseppe Micali, MD

Dermatology Clinic, University of Catania AOU Policlinico-Vittorio Emanuele

Via Santa Sofia, 78, IT-95123 Catania (Italy)

E-Mail cldermct@gmail.com 
mid-adulthood (age 30-60 years) [2-4]. In infants, SD frequently follows an uneventful course, and generally clears by 6-12 months of age (3 months in most Asian infants) [5]. It may appear again in individuals in their teens and twenties and may then generally follow a waxing and waning course throughout adulthood.

The distribution of SD is typically symmetrical and lesions range from being mild, patchy, and scaling to being widespread, thick, and with adherent crusts $[1,2]$. The lesions may have a red, smooth, glazed appearance in skin folds. SD of the trunk may appear in the presternal area and in body folds, including the axillae, navel, groin, and inframammary and anogenital areas. Common sites of involvement are hairy areas of the head, including the scalp, the scalp margin, eyebrows, eyelashes, the moustache, the beard, along with the forehead, nasolabial folds, external ear canals, and postauricular creases $[2,5]$.

\section{Epidemiology of SD in Asia}

SD has been reported to affect approximately $1-5 \%$ of the population worldwide, depending on the country studied [1, 6-8]. A limited number of studies have investigated the epidemiology of SD in Asia [9-14]. In a Korean cross-sectional study of military personnel, SD was ranked as the third most troublesome skin disease after atopic dermatitis and tinea cruris; the prevalence of SD was $2.1 \%$ [9]. A study in India reported that $13.4 \%$ of children aged $<5$ years had SD, with the prevalence peaking during infancy and decreasing steadily with age [10]. In Indian adults with scalp dermatoses, $18.7 \%$ of cases were attributed to SD [11]. Furthermore, data from Singapore revealed an SD prevalence of $3.2 \%$ in children but of $7.0 \%$ in adults [12]. In Asian individuals aged $12-20$ years, the prevalence of SD varied widely between tropical cities and countries (i.e., Macao 2.7\%, Guangzhou 2.9\%, Malaysia 17.2\%, and Indonesia 26.5\%) [13]. A cross-sectional study conducted in Japan found that the prevalence of SD among 67,448 patients attending hospital dermatology clinics was $3.28 \%$ [14]. The wide variation in prevalence rates obtained in these studies is likely to be a reflection of the high variability of the SD expression [15].

Similar to Western countries, in Asia there is an increased trend for SD in patients with immunosuppression (e.g., organ transplant recipients, AIDS patients), neurological or psychiatric conditions (e.g., Parkinson's disease, tardive dyskinesia, depression), or genetic disorders (e.g., Down's syndrome, cardiofaciocutaneous syn- drome) [16]. The prevalence of SD in HIV patients was reported as $47.0 \%$ in Thailand, $19.2 \%$ in Malaysia, and $17.0 \%$ in Korea [17-19].

\section{Differences between Asian and Non-Asian Skin}

Clinically significant differences between Asian and Caucasian skin have been reported, and these differences may impact the management of SD in Asians. The most obvious difference between ethnic groups relates to skin colour, secondary to the presence of melanin [20]. The photo-protective properties of melanin may influence the rate at which skin ages, with Caucasians showing an earlier onset of photo-aging than Asians [20, 21]. Asian skin is more prone to postinflammatory hyperpigmentation than Caucasian skin [20,22]. Differences have also been observed in the stratum corneum of Asians compared with that of non-Asians [20]. Although evidence regarding transepidermal water loss in Asian skin is contradictory, there are reports of Asians having a lower transepidermal water loss than other races [20]. However, a study in similarly aged Japanese and German women detected no significant differences in transepidermal water loss between the two races [23]. Similarly, there was no difference in transdermal water loss between Japanese and French volunteers whose physiological parameters were investigated at three different skin sites [24]. The interpretation of such data must take into account the ambient humidity, which can dramatically alter observations. Studies generally indicate that Asians have higher stratum corneum water content [25] and higher stratum corneum lipid levels than other races [20, 26, 27]. Investigations involving the removal of the stratum corneum by tape stripping indicated that Asian skin may have a poor barrier function [28-30]. Asians compared with non-Asians have a heightened dermatological response to irritants commonly found in topical, over-the-counter, or cosmetic preparations [23, 31-35]. In a study in Japanese patients with photo-damaged skin, tretinoin caused a higher than anticipated level of irritation than that previously reported in Caucasians [34]. In another study in which participants underwent a skin patch test on the forearm with sodium lauryl sulphate, significant subjective sensory differences were found between Japanese and German women [23]. Increased skin reactivity was observed in Asian subjects compared with Caucasian subjects in an analysis of results compiled from 9 acute irritation patch test studies [31]. Similarly, in a study involving 
Caucasian and Japanese women, the acute irritant response tended to be greater in the Japanese volunteers, reaching statistical significance with the stronger irritants [35]. Interestingly, 1 study reported no differences in skin pain perception between Chinese, Malay, and Indian participants [36]. Further well-designed studies comparing the structure and physiology of Asian skin with Caucasian skin are warranted.

\section{Pathogenesis of SD}

Although the general causes of SD, including interaction of Malassezia spp. with sebaceous lipids, seborrhoea, immune dysfunction, neurogenic factors, and emotional stress $[1,5,37]$, are considered similar in Asian and Western countries, ethnicity and geography are significant aspects determining the degree of pathogenic association between Malassezia spp. and SD. Both M. globosa and M. restricta are considered the predominant species in Western countries, whereas a relative predominance of $M$. restricta in lesional skin from SD patients is evident in East Asian countries [38-40]. In Korea, for example, analysis of scalp scales from SD patients revealed the presence of Malassezia spp. in $85 \%$ of cases, $M$. restricta in $47.5 \%$, but M. globosa in only $27.5 \%$ [39]. Conversely, in Thailand, a study in infants with SD showed a predominance of $M$. furfur [41].

The extent to which Malassezia spp. are associated with the presence of dandruff in SD patients also appears to vary markedly throughout Asia. For instance, Iranian researchers reported that only $24.5 \%$ of SD patients with dandruff had positive cultures for Malassezia spp. [42]. The corresponding percentage in an Indian study was $84 \%$, and Malassezia spp. density was significantly associated $(\mathrm{p}<0.001)$ with dandruff severity [43]. In addition, the rate of Malassezia spp. isolation from SD patients was significantly greater $(\mathrm{p}<0.01)$ in Southern rather than other regions of India [43]. Regional climatic conditions need to be taken into account when the pathogenesis of SD is being considered [10, 20]. Heat, humidity, and sweat are known to aggravate SD symptoms, especially scalp itch. Sunlight and the high ultraviolet index typical of tropical climates may also exacerbate SD symptoms. Overall, these findings suggest that regional differences in hereditary aspects of host susceptibility (e.g., skin constitution, inflammation) and in climatic conditions facilitating Malassezia spp. growth may affect local distribution and pathogenicity of this opportunistic pathogen. To clarify this

Management of Seborrhoeic Dermatitis in Asia contention, more specific studies are needed to assess species-specific molecular typing in large patient groups of diverse ethnicity.

\section{Treatment of SD}

The goal of SD treatment is not only to alleviate signs and symptoms of the condition but also to promote normalization of skin structure and function [44]. SD has been found to significantly impact a patient's quality of life [16], and treatment should be addressed to improve skin symptoms as well as quality of life.

In Western countries, topical treatments with antifungals and anti-inflammatory drugs have been extensively studied in patients with SD $[8,45,46]$. Although guidelines for the treatment of SD are generally lacking [8], recent evidence-based Danish guidelines have recommended antifungal azoles as first-line treatment [47]. The same paper indicates that a short course of topical corticosteroid or topical calcineurin inhibitors, both having an anti-inflammatory effect, may be considered beneficial [47]; systemic treatment of SD with oral antifungals may be advised in selected patients [47, 48].

\section{Treatment of SD in Asia: Critical Issues}

When treating Asian SD patients, the physician needs to consider not only the possible differences in aetiology between Asian and Western skin, but also a number of other sociological, economic, and cultural differences [49]. For example, the ratio of dermatologists to the overall population is very low in many Asian countries [49], meaning that most patients with SD are generally not treated by dermatologists. In addition, there is a wide availability of over-the-counter medications, cosmeceuticals, and generics as well as a variety of unproven and unorthodox treatments within Asia [49]. This may result in more Asian SD patients self-treating or seeking treatment from beauticians and other nonhealth-care personnel, therefore increasing the risk of irritating or inappropriate treatments [49]. In addition, significant differences in the acceptance, availability, and insurance support for treatment modalities for dermatological conditions vary from country to country within Asia [49].

In the light of the impact of these various factors, there is a need to have common treatment strategies for SD patients within Asian. Therefore, an expert consensus panel of twelve dermatologists from India, South Korea, Tai- 
Table 1. Treatment products for SD of the scalp and hairy areas

\begin{tabular}{|c|c|c|}
\hline $\begin{array}{l}\text { Mild SD } \\
\text { Topical antifungals }\end{array}$ & $\begin{array}{l}\text { Ciclopirox } 1-1.5 \% \text { shampoo } \\
\text { Ketoconazole } 1-2 \% \text { shampoo, } 2 \% \text { foaming gel, } \\
20 \mathrm{mg} / \mathrm{g} \text { hydrogel }\end{array}$ & $2-3$ times weekly \\
\hline AIAFp & $\begin{array}{l}\text { e.g. Piroctone olamine/bisabolol/ } \\
\text { glycyrrhetic acid/lactoferrin shampoo }\end{array}$ & $2-3$ times weekly \\
\hline Keratolytics & $\begin{array}{l}\text { Salicylic acid } 3 \% \text { shampoo } \\
\text { Tar } 1-2 \% \text { shampoo }\end{array}$ & $\begin{array}{l}\text { Salicylic acid: } 2-3 \text { times weekly } \\
\text { Tar: } 1-2 \text { times weekly }\end{array}$ \\
\hline Other agents & $\begin{array}{l}\text { Selenium sulphide } 2.5 \% \text { shampoo } \\
\text { Zinc pyrithione } 1-2 \% \text { shampoo }\end{array}$ & $2-3$ times weekly \\
\hline $\begin{array}{l}\text { Topical corticosteroids } \\
\text { (class I-II) }\end{array}$ & $\begin{array}{l}\text { Class I } \\
\text { Hydrocortisone } 1 \% \text { liniment and solution, } 0.1 \% \text { lotion } \\
\text { Class II } \\
\text { Alclometasone } 0.05 \% \text { ointment } \\
\text { Desonide } 0.05 \% \text { cream }\end{array}$ & Once daily for up to 4 weeks \\
\hline
\end{tabular}

Moderate-to-severe SD Topical corticosteroids (class I-II)

Class I

Hydrocortisone $1 \%$ liniment and solution, $0.1 \%$ lotion $\quad$ Once daily for up to 4 weeks Class II

Alclometasone $0.05 \%$ ointment

Desonide $0.05 \%$ cream

Topical corticosteroids (class III-IV)

Class III

Fluocinolone acetonide $0.01 \%$ shampoo Class IV

Clobetasol propionate $0.05 \%$ shampoo

Systemic antifungals Itraconazole 100-mg caps

Terbinafine 250-mg caps

Fluconazole 50-mg caps
Twice weekly, applied for 5 min, for 2 weeks

Twice weekly, applied for $5 \mathrm{~min}$, for 2 weeks

First month: $200 \mathrm{mg} /$ day for 1 week, then 200 $\mathrm{mg} /$ day for 2 days/month up to 11 months Continuous regimen: $250 \mathrm{mg} /$ day for 4-6 weeks

Intermittent regimen: $250 \mathrm{mg} /$ day for 12 days per month for 3 months

$50 \mathrm{mg} /$ day for 2 weeks or 200-300 mg weekly for 2-4 weeks wan, Malaysia, Vietnam, Singapore, Thailand, the Philippines, Indonesia, and Italy was convened in Singapore on the 26-27 September 2014.

\section{Consensus Recommendations for SD in Asia}

The specific practice recommendations identified by this consensus group for the treatment of SD in Asian adults and infants are outlined in the subsequent subsections. The panel used a consensus approach to determine recommendations about each clinical aspect addressed; this approach was based on grade levels in the Strengthof-Recommendation Taxonomy (SORT) scheme [50]. Each recommendation was also graded by the level of evidence according to the March 2009 Oxford Centre for Evidence-Based Medicine levels of evidence [51].

\section{Treatment}

SD of the Scalp and Hairy Areas

In adults, $\mathrm{SD}$ is a chronic condition that is likely to recur after treatment (category A, level 2b). Hence, patients should be counselled about the need for proper skin care [5]. Treatment selection should consider drug efficacy, 
Table 2. Treatment products for non-scalp SD

\begin{tabular}{|c|c|c|}
\hline Class of product & Formulation & Instructions for use \\
\hline \multicolumn{3}{|l|}{ Mild SD } \\
\hline Topical antifungals & $\begin{array}{l}\text { Ciclopirox } 1 \% \text { cream } \\
\text { Ketoconazole } 2 \% \text { cream }\end{array}$ & \multirow[t]{4}{*}{ Twice daily for 4 weeks } \\
\hline AIAFp & $\begin{array}{l}\text { e.g. Piroctone olamine/alglycera/ } \\
\text { bisabolol cream }\end{array}$ & \\
\hline Topical corticosteroids (class I) & Hydrocortisone $1 \%$ cream and ointment & \\
\hline Topical calcineurin inhibitors* & Tacrolimus $0.1 \%$ ointment & \\
\hline \multicolumn{3}{|l|}{ Moderate-to-severe SD } \\
\hline $\begin{array}{l}\text { Topical corticosteroids } \\
\text { (class II) }\end{array}$ & $\begin{array}{l}\text { Alclometasone } 0-05 \% \text { ointment } \\
\text { Desonide } 0.05 \% \text { cream }\end{array}$ & Twice daily for 4 weeks \\
\hline \multirow[t]{2}{*}{ Systemic antifungals } & Itraconazole 100-mg caps & $\begin{array}{l}\text { First month: } 200 \mathrm{mg} / \text { day for } 1 \text { week, then } 200 \mathrm{mg} \text { /day } \\
\text { for } 2 \text { days/month up to } 11 \text { months }\end{array}$ \\
\hline & Fluconazole 50 -mg caps & $\begin{array}{l}50 \mathrm{mg} / \text { day for } 2 \text { weeks or } 200-300 \mathrm{mg} \text { weekly for } 2-4 \\
\text { weeks }\end{array}$ \\
\hline
\end{tabular}

* Off-label use.

potential for side effects as well as cosmetic acceptability (category B, level 4). Wherever possible, patient selftreatment should be avoided, to minimize the likelihood of inappropriate treatment, SD symptom exacerbation, and variability in treatment response.

For SD of the scalp and hairy areas, the panel recommends the treatments summarized in table 1 (category A, level $1 b$ ). For mild forms, a topical approach is recommended starting with ketoconazole or ciclopirox, or alternatively selenium sulphide/zinc pyrithione, or keratolytic shampoos $[8,52]$. Similarly to non-scalp SD [53-56], non-steroidal and anti-inflammatory with antifungal properties (AIAFp) shampoo may represent a viable option, as reported in a recent randomized, single-blind clinical trial [57]. In case of failure, add a 4-week course with a weak-to-moderately potent corticosteroid [class I and II according to the Anatomical Therapeutic Chemical (ATC) classification by the World Health Organization (WHO)] followed by its gradual discontinuation [52].

For moderate-to-severe forms, especially if itchy, a combination of antifungal or AIAFp shampoo with weakto-moderately potent (class I-II) topical corticosteroids for up to 4 weeks is recommended [52]; in case of no improvement, consider to include in the weekly routine

Management of Seborrhoeic Dermatitis in Asia treatment with antifungal or AIAFp shampoo, 2 days of potent-to-very potent topical corticosteroid shampoo (class III and IV), containing fluocinolone acetonide $0.01 \%$ (class III) or clobetasol propionate $0.05 \%$ (class IV) for up to 2 weeks $[45,58-60]$ (category A, level 1b). In case of more resistant disease, systemic antifungals may be added $[47,48]$. For long-term maintenance, antifungal, AIAFp, or other shampoos active on SD may be used once or twice weekly (category B, level 5).

\section{SD of Non-Scalp Areas}

For SD of the non-scalp areas, the panel recommends the treatments summarized in table 2 (category A, level 1b). For the treatment of mild, non-scalp SD in adults, especially on the face, the use of antifungal creams (e.g., ketoconazole $2 \%$ cream, ciclopirox $1 \%$ cream) or AIAFp cream is preferred [52]. Topical antifungals represent the most common approach, and in the past years AIAFp cream has clearly demonstrated efficacy and tolerability in the treatment of mild-to-moderate SD of the face [53$56,61]$ (category A, level 1b). In case of failure, a combination of both antifungals and AIAFp agents may be considered. If no improvement is seen or in case a more rapid control of SD signs and symptoms is desired, a weakly potent topical corticosteroid (class I according to the 


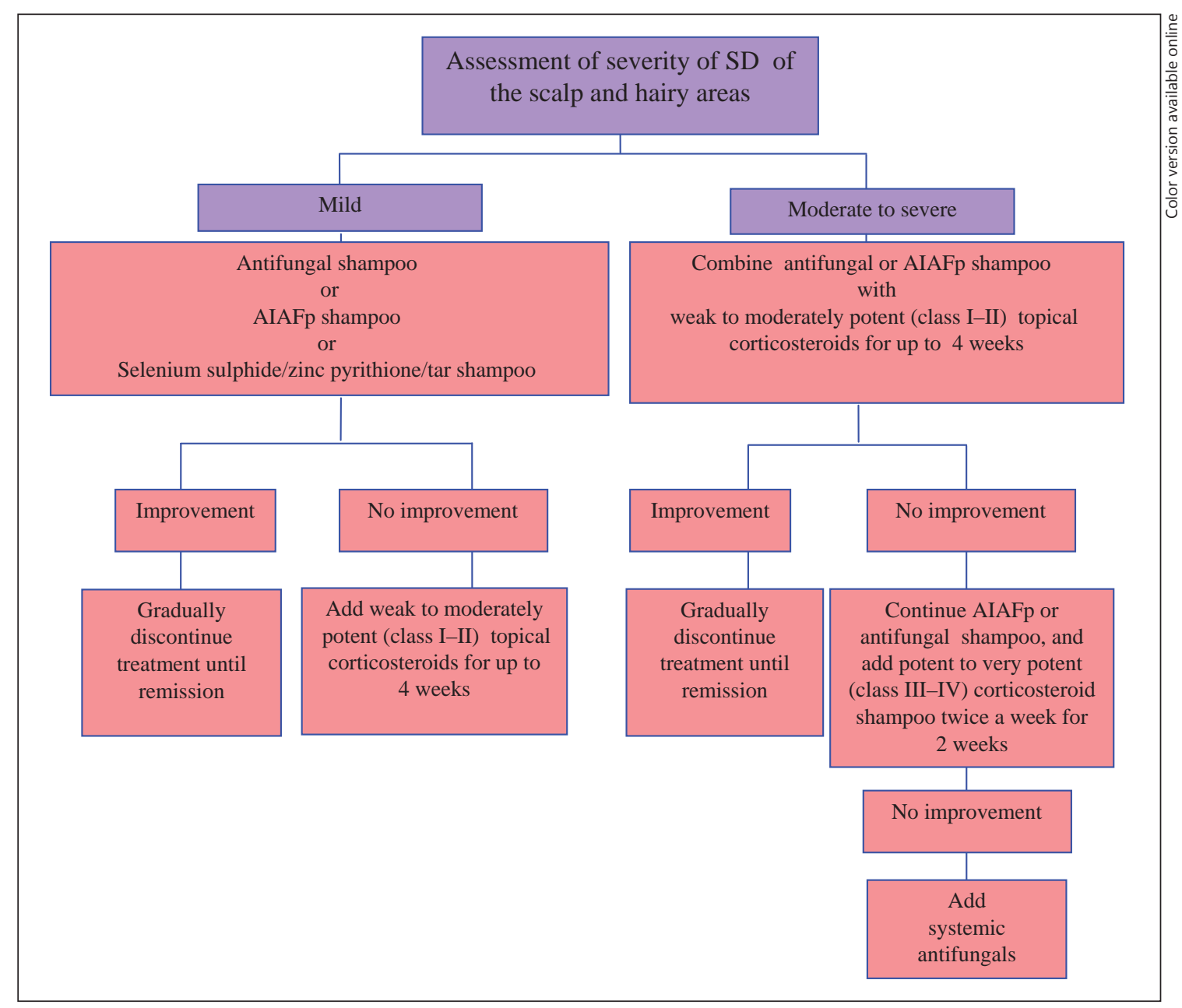

Fig. 1. Proposed therapeutic algorithm for adult SD of the scalp and hairy areas. AIAFp = Nonsteroidal anti-inflammatory agent with antifungal properties.

ATC by WHO) once or twice daily for up to 2 weeks may be added [4]. If successful, the use of a topical corticosteroid may be extended for an additional 2 weeks. The use of AIAFp cream may be considered for maintenance treatment.

For moderate-to-severe non-scalp SD, topical moderately potent corticosteroids (class II according to the ATC by WHO) may be used up to a maximum of 2 weeks in combination with AIAFp or topical antifungals. This approach will achieve the most rapid control of SD signs and symptoms. In case of clinical improvement, the use of a topical corticosteroid may be considered for an additional 2 weeks. If the response is not satisfactory, the use of systemic antifungals should be considered. Finally, topical calcineurin inhibitor agents may represent an alterna- tive for mild-to-severe SD refractory cases (category A, level $1 b)$.

The above recommendations are summarized in figures 1 and 2.

\section{Treatment in Infants}

SD of the Scalp and Hairy Areas

SD management in infants involves advising simple measures, such as regular washing of the scalp with baby shampoo and gentle brushing to loosen scales [62]. The daily use of white petrolatum may help to soften scales. If these measures are not effective, ketoconazole $2 \%$ shampoo could be used until the condition resolves $[62,63]$ (category A, level 1b). The clinical efficacy of AIAFp cream in infants has been demonstrated in a multicentre, 


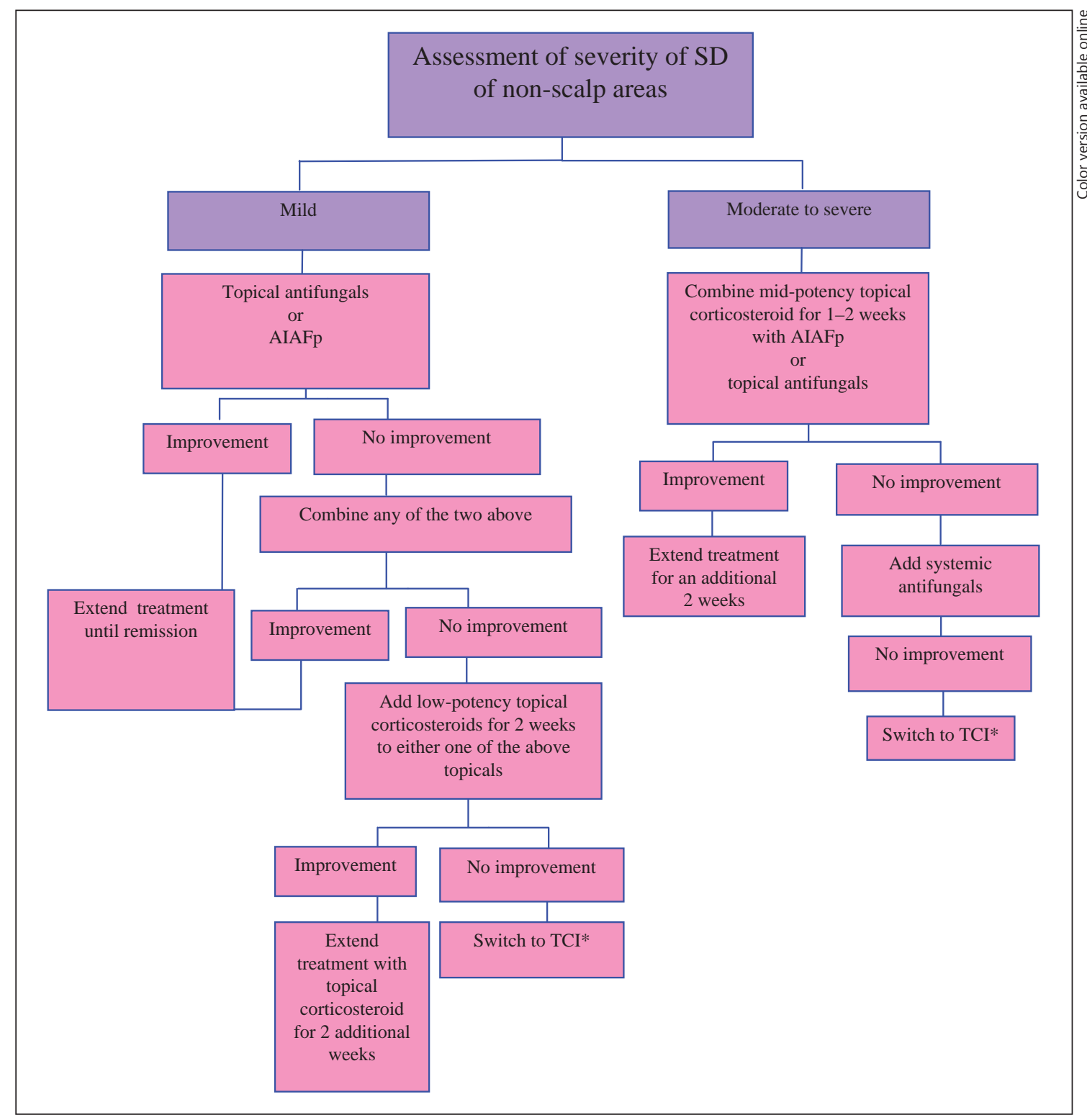

Fig. 2. Proposed therapeutic algorithm for adult non-scalp SD. AIAFp = Nonsteroidal anti-inflammatory agent with antifungal properties; TCI = topical calcineurin inhibitors. * Off-label use.

double-blind, placebo-controlled, parallel-group study in infants with cradle cap, in whom there was a significant difference in the reduction of scaling between the treatment and placebo groups [64].

\section{SD of Non-Scalp Areas}

The use of ketoconazole $2 \%$ cream is advised alone or together with a weakly potent topical corticosteroid (class I according to the ATC by WHO) [65] (category A, level 5).

All therapeutic options are listed in table 3.

\section{Conclusions}

Because the skin of Asians compared with non-Asians is more reactive to irritants, topical agents with irritant potential, and therefore with the likelihood to complicate SD lesions [31], should be avoided. In particular, cosmetic products containing alcohol, soap and shaving cream, greasy emollients, and any known trigger factors, if they cause irritation, should be changed for more gentle products. Finally, the presence of dry or damp conditions in 
Table 3. Treatment products for infantile SD

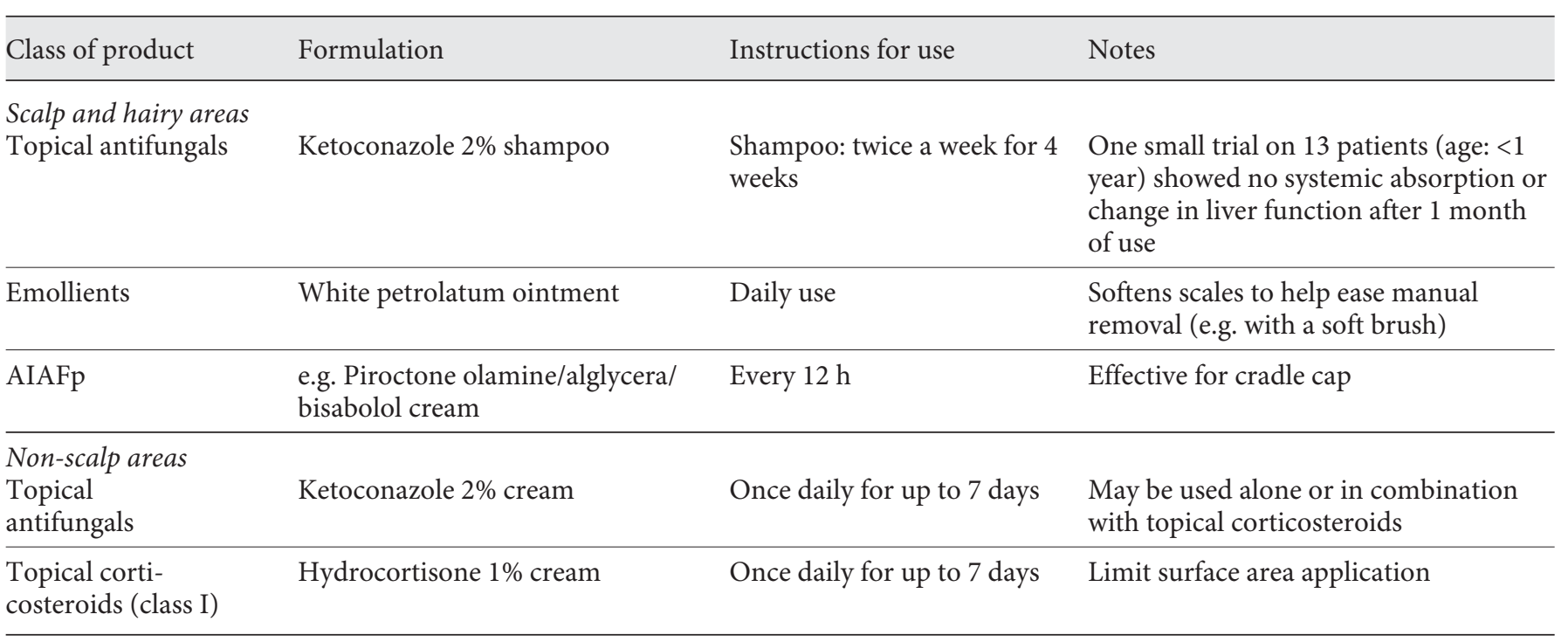

the workplace/living place, a facilitating factor for SD common in many Asia countries, should also be considered [66] (category B, level 5).

\section{Acknowledgments}

Editorial support for the preparation of this manuscript was given by Dr. Dennis Malvin H. Malgapo of MIMS Pte. Ltd. through an unrestricted educational grant by A. Menarini Asia-Pacific Pte. Ltd.

\section{Statement of Ethics}

Published research complies with the guidelines for human studies and animal welfare regulations.

\section{Disclosure Statement}

The authors have received honoraria for their participation in the Asia Pacific Seborrheic Dermatitis Leaders' Summit 2014. Dr. Wai Kwong Cheong is a speaker for Galderma and for L'Oréal and a member of the Advisory Board for P \& G Olay Pro-X Global Dermatologist Alliance.

\section{References}

1 Naldi L: Seborrhoeic dermatitis. BMJ Clin Evid 2010;2010:pii1713.

2 Dessinioti C, Katsambas A: Seborrheic dermatitis: etiology, risk factors, and treatments: facts and controversies. Clin Dermatol 2013; 31:343-351

3 Schwartz RA, Janusz CA, Janniger CK: Seborrheic dermatitis: an overview. Am Fam Physician 2006; 74:125-130.

4 Del Rosso JQ: Adult seborrheic dermatitis: a status report on practical topical management. J Clin Aesthet Dermatol 2011;4:32-38.

5 Johnson BA, Nunley JR: Treatment of seborrheic dermatitis. Am Fam Physician 2000;61: 2703-2710, 2713-2714.

6 Apasrawirote W, Udompataikul M, Rattanamongkolgul S: Topical antifungal agents for seborrheic dermatitis: systematic review and meta-analysis. J Med Assoc Thai 2011;94: 756-760.
7 Gupta AK, Madzia SE, Batra R: Etiology and management of seborrheic dermatitis. Dermatology 2004;208:89-93.

8 Okokon EO, Verbeek JH, Ruotsalainen JH, Ojo OA, Bakhoya VN: Topical antifungals for seborrhoeic dermatitis. Cochrane Database Syst Rev 2015;5:CD008138.

9 Bae JM, Ha B, Lee H, Park CK, Kim HJ, Park YM: Prevalence of common skin diseases and their associated factors among military personnel in Korea: a cross-sectional study. J Korean Med Sci 2012;27:1248-1254.

10 Banerjee S, Gangopadhyay DN, Jana S, Chanda M: Seasonal variation in pediatric dermatoses. Indian J Dermatol 2010;55:44-46.

11 Pillai J, Okade R: A clinical spectrum of scalp dermatoses in adults presenting to a tertiary referral care centre. Int J Biol Med Res 2014; 5:4434-4439.
12 Goh CL, Akarapanth R: Epidemiology of skin disease among children in a referral skin clinic in Singapore. Pediatr Dermatol 1994;11: 125-128.

13 Yuan S-H, Zhang H, Chen Q-I: The prevalence and risk factors analysis of adolescent seborrheic dermatitis in tropical and subtropical areas. Chin J Dermatovenereol 2008; 12.

14 Furue M, Yamazaki S, Jimbow K, Tsuchida T, Amagai M, Tanaka T, Matsunaga K, Muto M, Morita E, Akiyama M, Soma Y, Terui T, Manabe M: Prevalence of dermatological disorders in Japan: a nationwide, cross-sectional, seasonal, multicenter, hospital-based study. J Dermatol 2011;38:310-320.

15 Naldi L, Rebora A: Clinical practice. Seborrheic dermatitis. N Engl J Med 2009;360:387396. 
16 Szepietowski JC, Reich A, Wesolowska-Szepietowska E, Baran E: Quality of life in patients suffering from seborrheic dermatitis: influence of age, gender and education level. Mycoses 2009;52:357-363.

17 Wiwanitkit V: Prevalence of dermatological disorders in Thai HIV-infected patients correlated with different $\mathrm{CD} 4$ lymphocyte count statuses: a note on 120 cases. Int J Dermatol 2004; $43: 265-268$

18 Jing W: A retrospective survey of mucocutaneous manifestations of HIV infection in $\mathrm{Ma}$ laysia: analysis of 182 cases. J Dermatol 2000; 27:225-232.

19 Kim TG, Lee KH, Oh SH: Skin disorders in Korean patients infected with human immunodeficiency virus and their association with a CD4 lymphocyte count: a preliminary study. J Eur Acad Dermatol Venereol 2010; 24:1476-1480.

20 Rawlings AV: Ethnic skin types: are there differences in skin structure and function? Int J Cosmet Sci 2006;28:79-93.

21 Timilshina S, Bhuvan KC, Khanal M, Marshani B, Paudyal BR, Skalko-Basnet N: The influence of ethnic origin on the skin photoageing: Nepalese study. Int J Cosmet Sci 2011; 33:553-559.

22 Davis EC, Callender VD: Postinflammatory hyperpigmentation: a review of the epidemiology, clinical features, and treatment options in skin of color. J Clin Aesthet Dermatol 2010; 3:20-31.

23 Aramaki J, Kawana S, Effendy I, Happle R, Loffler H: Differences of skin irritation between Japanese and European women. Br J Dermatol 2002;146:1052-1056.

24 Yamashita Y, Okano Y, Ngo T, Buche P, Sirvent A, Girard F, Masaki H: Differences in susceptibility to oxidative stress in the skin of Japanese and French subjects and physiological characteristics of their skin. Skin Pharmacol Physiol 2012;25:78-85.

25 Sugino K, Imokawa G, Maibach HI: Ethnic difference of stratum corneum lipid in relation to stratum corneum function. J Invest Dermatol 1993;100:587.

26 Pappas A, Fantasia J, Chen T: Age and ethnic variations in sebaceous lipids. Dermatoendocrinology 2013;5:319-324

27 Wan DC, Wong VW, Longaker MT, Yang GP, Wei FC: Moisturizing different racial skin types. J Clin Aesthet Dermatol 2014;7:25-32.

28 Kompaore F, Tsuruta H: In vivo differences between Asian, black and white in the stratum corneum barrier function. Int Arch Occup Environ Health 1993;65:S223-S225.

29 Kompaore F, Marty JP, Dupont C: In vivo evaluation of the stratum corneum barrier function in blacks, Caucasians and Asians with two noninvasive methods. Skin Pharmacol 1993;6:200-207.

30 Muizzuddin N, Hellemans L, Van Overloop L, Corstjens H, Declercq L, Maes D: Structural and functional differences in barrier properties of African American, Caucasian and East Asian skin. J Dermatol Sci 2010;59:123-128.
31 Robinson MK: Population differences in acute skin irritation responses. Race, sex, age, sensitive skin and repeat subject comparisons. Contact Dermatitis 2002;46:86-93.

32 Goh CL, Tang MB, Briantais P, Kaoukhov A, Soto P: Adapalene gel $0.1 \%$ is better tolerated than tretinoin gel $0.025 \%$ among healthy volunteers of various ethnic origins. J Dermato$\log$ Treat 2009;20:282-288.

33 Modjtahedi SP, Maibach HI: Ethnicity as a possible endogenous factor in irritant contact dermatitis: comparing the irritant response among Caucasians, blacks, and Asians. Contact Dermatitis 2002;47:272-278.

34 Tadaki T, Watanabe M, Kumasaka K, Tanita Y, Kato T, Tagami H, Horii I, Yokoi T, Nakayama Y, Kligman AM: The effect of topical tretinoin on the photodamaged skin of the Japanese. Tohoku J Exp Med 1993;169:131-139.

35 Foy V, Weinkauf R, Whittle E, Basketter DA: Ethnic variation in the skin irritation response. Contact Dermatitis 2001;45:346-349.

36 Yosipovitch G, Meredith G, Chan YH, Goh CL: Do ethnicity and gender have an impact on pain thresholds in minor dermatologic procedures? A study on thermal pain perception thresholds in Asian ethnic groups. Skin Res Technol 2004;10:38-42.

37 Schwartz JR: Treatment of seborrheic dermatitis of the scalp. J Cosmet Dermatol 2007;6: $18-22$.

38 Tajima M, Sugita T, Nishikawa A, Tsuboi R: Molecular analysis of Malassezia microflora in seborrheic dermatitis patients: comparison with other diseases and healthy subjects. J Invest Dermatol 2008;128:345-351.

39 Lee YW, Byun HJ, Kim BJ, Kim DH, Lim YY, Lee JW, Kim MN, Kim D, Chun YJ, Mun SK, Kim CW, Kim SE, Hwang JS: Distribution of Malassezia species on the scalp in Korean seborrheic dermatitis patients. Ann Dermatol 2011;23:156-161.

40 Tanaka A, Cho O, Tsuboi R, Kurakado S, Sugita T: Molecular characterization of the skin fungal microbiota in patients with seborrheic dermatitis. J Clin Exp Dermatol Res 2014;5: 239.

41 Wananukul S, Chindamporn A, Yumyourn P, Payungporn S, Samathi C, Poovorawan Y: Malassezia furfur in infantile seborrheic dermatitis. Asian Pac J Allergy Immunol 2005; 23:101-105.

42 Zarei-Mahmoudabadi A, Zarrin M, Mehdinezhad F: Seborrheic dermatitis due to Malassezia species in Ahvaz, Iran. Iran J Microbiol 2013;5:268-271.

43 Rudramurthy SM, Honnavar P, Dogra S, Yegneswaran PP, Handa S, Chakrabarti A: Association of Malassezia species with dandruff. Indian J Med Res 2014;139:431-437.

44 Schwartz JR, Messenger AG, Tosti A, Todd G, Hordinsky M, Hay RJ, Wang X, Zachariae C, Kerr KM, Henry JP, Rust RC, Robinson MK: A comprehensive pathophysiology of dandruff and seborrheic dermatitis - towards a more precise definition of scalp health. Acta Derm Venereol 2013;93:131-137.
45 Kastarinen H, Okokon EO, Verbeek JH: Topical anti-inflammatory agents for seborrheic dermatitis of the face or scalp: summary of a Cochrane Review. JAMA Dermatol 2015;151: 221-222.

46 Fabbrocini G, Cantelli M, Monfrecola G: Topical nicotinamide for seborrheic dermatitis: an open randomized study. J Dermatolog Treat 2014;25:241-245.

47 Hald M, Arendrup MC, Svejgaard EL, Lindskov R, Foged EK, Saunte DM: Evidence-based Danish guidelines for the treatment of Malassezia-related skin diseases. Acta Derm Venereol 2015;95:12-19.

48 Gupta AK, Richardson M, Paquet M: Systematic review of oral treatments for seborrheic dermatitis. J Eur Acad Dermatol Venereol 2014;28:16-26

49 Abad-Casintahan F, Chow SK, Goh CL, Kubba R, Miyachi Y, Noppakun N, See J, Suh DH, Yang LC, Kang S: Toward evidence-based practice in acne: consensus of an Asian Working Group. J Dermatol 2011;38:1041-1048.

50 Ebell MH, Siwek J, Weiss BD, Woolf SH, Susman J, Ewigman B, Bowman M: Strength of recommendation taxonomy (SORT): a patient-centered approach to grading evidence in the medical literature. J Am Board Fam Pract 2004;17:59-67.

51 Howick J, Chalmers I, Glasziou P, Greenhalgh T, Heneghan C, Liberati A, Moschetti I, Phillips B, Thornton H, Goddard O, Hodgkinson M: Oxford Centre for Evidence-based Medicine - Levels of Evidence (March 2009). 2009. http://www.cebm.net/oxford-centre-evidence-based-medicine-levels-evidencemarch-2009/.

52 Kastarinen H, Oksanen T, Okokon EO, Kiviniemi VV, Airola K, Jyrkka J, Oravilahti T, Rannanheimo PK, Verbeek JH: Topical antiinflammatory agents for seborrhoeic dermatitis of the face or scalp. Cochrane Database Syst Rev 2014;5:CD009446.

53 Veraldi S, Menter A, Innocenti M: Treatment of mild to moderate seborrhoeic dermatitis with MAS064D (Sebclair), a novel topical medical device: results of a pilot, randomized, double-blind, controlled trial. J Eur Acad Dermatol Venereol 2008;22:290-296.

54 Nalamothu V, O'Leary AL, Kandavilli S, Fraser J, Pandya V: Evaluation of a nonsteroidal topical cream in a guinea pig model of Malassezia furfur infection. Clin Dermatol 2009. 27:S41-S43.

55 Kircik L: An open-label, single-center pilot study to determine the antifungal activity of a new nonsteroidal cream (Promiseb Topical Cream) after 7 days of use in healthy volunteers. Clin Dermatol 2009;27:S44-S47.

56 Elewski B: An investigator-blind, randomized, 4-week, parallel-group, multicenter pilot study to compare the safety and efficacy of a nonsteroidal cream (Promiseb Topical Cream) and desonide cream $0.05 \%$ in the twice-daily treatment of mild to moderate seborrheic dermatitis of the face. Clin Dermatol 2009;27:S48-S53. 
57 Dall'Oglio F, Lacarrubba F, Verzì AE, Micali G: Noncorticosteroid combination shampoo versus $1 \%$ ketoconazole shampoo for the management of mild-to-moderate seborrheic dermatitis of the scalp: results from a randomized, investigator-single-blind trial using clinical and trichoscopic evaluation. Skin Appendage Disord 2015;1:126-130.

58 Ramirez RG, Dorton D: Double-blind placebo-controlled multicentre study of fluocinolone acetonide shampoo (FS shampoo) in scalp seborrhoeic dermatitis. J Dermatol Treat 1993;4:135-137.

59 Reygagne P, Poncet M, Sidou F, Soto P: Clobetasol propionate shampoo $0.05 \%$ in the treatment of seborrheic dermatitis of the scalp: results of a pilot study. Cutis 2007;79: 397-403.
60 Ortonne JP, Nikkels AF, Reich K, Ponce Olivera $R M$, Lee $J H$, Kerrouche N, Sidou F, Faergemann J: Efficacious and safe management of moderate to severe scalp seborrhoeic dermatitis using clobetasol propionate shampoo $0 \cdot 05 \%$ combined with ketoconazole shampoo $2 \%$ : a randomized, controlled study. Br J Dermatol 2011;165:171-176.

61 Dall'Oglio F, Tedeschi A, Guardabasso V, Micali G: Evaluation of a topical anti-inflammatory/antifungal combination cream in mildto-moderate facial seborrheic dermatitis: an intra-subject controlled trial examining treated vs. untreated skin utilizing clinical features and erythema-directed digital photography. J Clin Aesthet Dermatol 2015;8:33-38.

62 O'Connor NR, McLaughlin MR, Ham P: Newborn skin. I. Common rashes. Am Fam Physician 2008;77:47-52.
63 Brodell RT, Patel S, Venglarcik JS, Moses D, Gemmel D: The safety of ketoconazole shampoo for infantile seborrheic dermatitis. Pediatr Dermatol 1998;15:406-407.

64 David E, Tanuos H, Sullivan T, Yan A, Kircik LH: A double-blind, placebo-controlled pilot study to estimate the efficacy and tolerability of a nonsteroidal cream for the treatment of cradle cap (seborrheic dermatitis). J Drugs Dermatol 2013;12:448-452.

65 Wannanukul S, Chiabunkana J: Comparative study of $2 \%$ ketoconazole cream and $1 \%$ hydrocortisone cream in the treatment of infantile seborrheic dermatitis. J Med Assoc Thai 2004;87(suppl 2):S68-S71.

66 Peyri J, Lleonart M: Clinical and therapeutic profile and quality of life of patients with seborrheic dermatitis. Actas Dermosifiliogr 2007;98:476-482. 